by the academic units deals with topics of the utmost importance and is carried out to the highest academic standards. The units deserve better funding.

RAYMOND HOFFENBERG

President,

Royal College of Physicians,

London NW1 4LE

\section{Severity scoring in intensive} care

Intensive care is demanding in both human and financial terms. Ethical considerations, common sense, and economic concerns all require that expensive resources should be concentrated on patients with potentially recoverable disease and not squandered on those with a manifestly hopeless prognosis—or used unnecessarily to "monitor" patients who are no more than at risk of developing a critical, life threatening illness. ${ }^{12}$ These categories are difficult to define precisely, and there is an understandable reluctance to withhold or-more difficult-withdraw treatment when there seems the slightest chance of ultimate recovery. The temptation to strive for survival at all costs is difficult to resist, even when there is no precedent for recovery, ${ }^{3}$ and unproved, extravagant remedies are likely to be tried as a last resort.

Clinicians faced with these difficult decisions may be helped by guidelines based on careful analysis of results achieved in comparable groups treated by different meansan approach as valid for intensive care as for other disciplines. Accurate comparisons are difficult, however, because multisystem disease and rapid change are common.

Various methods of prediction have been devised to deal with these difficulties. Some are applicable only to specific conditions, ${ }^{4-7}$ while others require the collection of very detailed information. ${ }^{8}$ One of the most widely used is the Glasgow coma scale, calculated from simple variables determined by clinical examination. ${ }^{9}$ Prognostic information has been derived from a data bank of more than 1000 patients with head injury by relating the severity of the initial insult to subsequent outcome, ${ }^{10}$ and this information has then been used to compare the results of different forms of treatment. ${ }^{11}$ Similar methods were used by Levy et al to predict outcome from non-traumatic coma ${ }^{12}$ and, more recently, to suggest individual prognosis after cardiac arrest. ${ }^{13}$

Specific scoring systems provide a means for comparing results and ensuring consistent standards, ${ }^{14}$ but they are applicable to only a few patients. A more general indication of severity of illness and consumption of resources is given by the therapeutic intervention scoring system, which is calculated from the frequency with which certain procedures and treatments are performed for each patient ${ }^{15}{ }^{16}$; but its value is diminished by differences in medical practice among centres and within one centre with time.

Knaus and his colleagues suggested that the severity of acute disease could be assessed by measuring the degree of abnormality of several physiological variables. ${ }^{17}$ They defined an acute physiology score derived from points scored for the extent of abnormality of 34 variables, and combined it with a rating for age and chronic health to formulate the acute physiology and chronic health evaluation (APACHE I) classification. Higher scores, indicating greater severity of illness, were associated with an increased mortality in hospital. The complexity of calculating the acute physiology score prompted simplifications, ${ }^{18}{ }^{19}$ most notably by Knaus $e t$ $a l$, who used the 12 most important and commonly recorded variables to create a shortened scoring system, APACHE II. Application of APACHE II to nearly 6000 patients in 13 American intensive care units showed its reliability for stratifying the degree of risk of subsequent death from a wide range of disorders. ${ }^{20}$ Similar physiological criteria have been used to define acute organ system failure and, by recording serial data, to relate prognosis to the number of systems affected and the duration of failure of each. ${ }^{21}$

The APACHE score is an index of risk on a population basis. Though it may contribute to decision making, ${ }^{22}$ it cannot be expected to provide an accurate individual prognosis. The importance of any physiological derangement is influenced by the nature of the underlying condition, and the APACHE score must be weighted by an appropriate factor before disease specific mortality predictions can be even contemplated. Acquisition of a large data bank is necessary for the assessment of specific risk, particularly for disorders which are rare or associated with a low mortality.

The APACHE scoring system is a powerful tool for clinical audit ${ }^{23}$ and for comparing different policies and treatment regimens. ${ }^{24}$ The decision by the Intensive Care Society to promote its use in the United Kingdom should be welcomed as a means of improving standards, rationalising the use of an expensive commodity, and ensuring that management is appropriate to individual needs and wishes.

C J MORGAN Doverdale fellow

M A BRanthwaIte

Doverdale Intensive Care Unit,

Brompton Hospital,

London SW'3 6HP

Anonymous. Intensive care audit [Editorial]. Lancet 1985;i:1428-9.

Jennett B. Inappropriate use of intensive care. Br Med J 1984;289:1709-11.

Schuster DP, Marion JM. Precedents for meaningful recovery during treatment in a medical intensive care unit: outcome in patients with hematologic malignancy. Am f Med 1983;75: 402-6.

4 Champion HR, Sacco WJ, Carnazzo AJ, Copes W, Fouty WJ. Trauma score. Crit Care Med $1981 ; 9: 672-6$.

Baker SP, O'Neil B, Haddum W, Long WB. The injury severity score: a method for describing patients with multiple injuries and evaluating emergency care. $\mathcal{F}$ Trauma 1974;14:187-96.

6 Elebute EA, Stoner HB. The grading of sepsis. Br f Surg 1983;70:29-31.

7 Feller I, Crane KH. National burn information exchange. Med Clin North Am 1970;50:1425-36.

8 Bland RD, Shoemaker WC, Abraham E, Cobo JC. Hemodynamic and oxygen transport patterns in surviving and nonsurviving postoperative patients. Crit Care Med 1985;13:85-90.

9 Teasdale G, Jennett B. Assessment of coma and impaired consciousness. A practical scale. Lancet 1974; ii: $81-4$.

10 Jennett B, Teasdale G, Braakman R, Minderhoud J, Heiden J, Kurze T. Prognosis of patients with severe head injury. Neurosurgery 1979;4:283-9.

11 Jennett B, Teasdale G, Fry J, et al. Treatment for severe head injury. I Neurol Neurosurg Psychiatry 1980;43:289-95.

12 Levy DE, Bates D, Caronna JJ, et al. Prognosis in non-traumatic coma. Ann Intern Med 1981;94:293-301.

13 Levy DE, Caronna JJ, Singer BH, Lapinski RH, Frydman H, Plum F. Predicting outcome from hypoxic-ischemic coma. FAMA 1985;253:1420-6.

4 Watt I, Ledingham IMcA. Mortality amongst multiple trauma patients admitted to an intensive therapy unit. Anaesthesia 1984;39:973-81.

15 Cullen DJ, Civetta JM, Briggs BA, Ferrara LC. Therapeutic intervention scoring system: a method for quantitative comparison of patient care. Crit Care Med 1974;2:57-60.

16 Keene AR, Cullen DJ. Therapeutic intervention scoring system: update. Crit Care Med 1983;11:1-3.

17 Knaus WA, Zimmerman JE, Wagner DP, Draper EA, Lawrence D. APACHE-acute physiology and chronic health evaluation: a physiologically based classification system. Crit physiology and chronic
Care Med 1981;9:591-7.

18 Le Gall JR, Loirat P, Alperovitch A, et al. A simplified acute physiology score for ICU patients. Crit Care Med 1984;12:975-7.

19 Bion JF, Edlin SA, Ramsay G, McCabe S, Ledingham IMcA. Validation of a prognostic score in critically ill patients undergoing transport. Br Med $\mathcal{F} 1985 ; 291: 432-4$.

20 Knaus WA, Draper EA, Wagner DP, Zimmerman JE. Apache II: a severity of disease classification system. Crit Care Med 1985;13:818-29.

21 Knaus WA, Draper EA, Wagner DP, Zimmerman JE. Prognosis in acute organ-system failure. Ann Surg 1985;202:685-93.

22 Zimmerman JE, Knaus WA, Sharpe SM, et al. The use and implications of "do not resuscitate" orders in intensive care units. FAMA 1986;255:351-6.

23 Knaus WA, Draper EA, Wagner DP, Zimmerman JE. Evaluation of outcome from intensive care in major medical centers. Ann Intern Med (in press)

24 Knaus WA, Wagner DP, Loirat $P$, et al. A comparison of intensive care in the USA and France. Lancet 1983;ii:642-6. 